\title{
Investigando a presença das referências greco-latinas no ensino de língua e literatura portuguesa nos níveis fundamental e médio
}

\author{
Alessandra Leles Rocha \\ Universidade Federal de Uberlândia - UFU \\ Maria Marta Carrijo de Oliveira \\ Universidade Federal de Uberlândia - UFU
}

\begin{abstract}
Resumo
Este trabalho relata a atividade de conclusão proposta pela disciplina PIPE 3 - Projeto Integrado de Práticas Educativas / Estudos Clássicos na Aprendizagem de Língua Portuguesa e de Literatura, oferecida pelo curso de Letras, da Universidade Federal de Uberlândia. Tal atividade foi composta por três etapas, sendo estas uma visita a uma biblioteca de escola pública para levantamento de obras relacionadas à Literatura Greco-Latina; a análise de livros didáticos de Literatura e Português (Ensino Médio) em relação aos textos traduzidos ou adaptados a partir de obras gregas e latinas; e, entrevista com educadores de escola pública sobre o modo de elaboração do material de aula (complementar ao livro didático escolhido), quanto à utilização de textos referentes a algum gênero literário grego e/ou latino. Os resultados apontaram para uma série de fragilidades importantes no processo de construção linguística do aluno, dada a carência das bases greco-latinas para o aprendizado da Língua Portuguesa.
\end{abstract}

Palavras-chave: Ensino-aprendizagem. Estudos clássicos. Língua portuguesa. Formação docente.

\begin{abstract}
This paper reports on the final activity for PIPE 3 - Integrated Project of Educational Practices / Classical Studies in Learning Portuguese Language and Literature, offered by the course of Language at the Federal University of Uberlândia. The activity was composed of three stages. The first stage was a visit to a public school library to survey works related to Greco-Latin Literature. The second was the analysis of textbooks of Literature and Portuguese (High School) in relation to texts translated or adapted from Greek and Latin works. The third stage was an interview with public school educators about how to prepare the class material (complementary to the chosen textbook), regarding the use of texts referring to some Greek and / or Latin literary genre. The results point to a series of important weaknesses in the students' process of linguistic construction, given the lack of GrecoLatin bases for learning the Portuguese language.
\end{abstract}

Key-words: Teaching-learning. Classical studies. Portuguese language. Teacher training.

\section{INTRODUÇÃO}

Segundo o Projeto Político Pedagógico do Curso de Letras (2007), da Universidade Federal de Uberlândia, a proposta do PIPE - Projeto Integrado de Práticas 
Educativas, que trata dos Estudos Clássicos na Aprendizagem de Língua Portuguesa e de Literatura, possibilita ao aluno o início de um contato com as condições de trabalho do professor de ensino fundamental e médio, bem como os recursos (materiais e humanos) que lhes são propiciados (ou negados) para uma contínua formação e atualização no conhecimento dos fundamentos teóricos de literatura clássica grecolatina.

Estão incluídas nesse processo de aprendizagem as seguintes possibilidades: consulta as bibliotecas de escolas públicas e privadas de Ensino Fundamental e Médio; análise de livros didáticos de Literatura e Português (Ensino Fundamental e Médio); e, entrevista com algum educador de escola pública ou privada (Ensino Fundamental e Médio) sobre o modo de elaboração do material de aula (complementar ao livro didático escolhido), quanto à utilização de textos referentes a algum gênero literário grego e/ou latino.

Assim, optamos pelo desenvolvimento de um trabalho de conclusão que contemplasse as três possibilidades citadas anteriormente, objetivando que a análise da situação dos estudos clássicos (greco-latino) no contexto do ensino de Língua Portuguesa e de Literatura no ensino básico (Fundamental e/ou Médio) brasileiro, pautada em mais de um aspecto, pudesse melhor inferir se a presença de elementos indicadores desses estudos é satisfatória ou não para contribuir com a aprendizagem dos alunos e/ou se necessita de suporte adicional.

\section{FUNDAMENTAÇÃO TEÓRICA}

\section{A importância das referências Greco-Latinas na construção da Língua Materna}

A partir de 1961, quando entrou em vigor a Lei de Diretrizes e Bases da Educação 4024/61, o Latim deixou de ser disciplina obrigatória do ensino fundamental e a partir de então, deixou de existir no ensino básico nacional.

Se para alguns isso representou um alívio em relação ao rigor da cobrança imposta por tal conteúdo; a verdade é que o banimento do latim representou uma perda significativa ao estudo das Línguas.

Para muitas áreas do conhecimento, como acontece na Biologia, no Direito e em Letras, o Latim é parte integrante e seu conhecimento é fundamental na facilitação do processo de aprendizagem. Como explica Longo (2014), 
O motivo pelo qual, ainda hoje, se formam nos cursos de Letras do País especialistas em Língua e Literatura Latinas é a conservação e a transmissão da herança literária deixada pelos antigos romanos. Entende-se que o estudo do latim, nesse contexto, deve colocar o aprendiz em contato com os registros textuais, mais do que isso, porém, deve levá-lo a perceber a densidade humana nas manifestações dessa cultura antiga. Em razão disso, entende-se que o ensino desse idioma deve prever ainda a internalização dos conceitos necessários à reflexão sobre linguagem verbal tomada como objeto do saber humano, requisito de uma boa formação nessa área do conhecimento (LIMA, 1992, p.11). (LONGO, 2014, p.176).

Dentro desse contexto é que se fundamenta a necessidade de manter uma base essencial de conhecimento das referências Greco-Latinas, nos dias de hoje. Parte do desinteresse e da desmotivação de muitos alunos em relação ao aprendizado, seja da Língua Materna ou de outros conteúdos dependentes dela, está relacionada à falta de elementos que estabeleçam sentido lógico a esse processo; algo que o conhecimento contextualizado do Latim pode facilmente auxiliar. Segundo Viaro (1999),

\footnotetext{
Com o latim aprenderemos a compreender melhor o nosso idioma, que contém mistérios interessantíssimos. O latim serve-nos de trampolim para mergulhos mais profundos na nossa visão de mundo, no nosso modo de pensar, na nossa vida. Aquele que entende bem a mensagem que o latim passa em seus textos se questionará melhor e verá que antes de nossos valores, havia outros, muito distintos, mas perfeitamente coerentes, que merecem nossa admiração e respeito. Longe de ser retrógrado, o estudo do latim associado ao estudo da vida social em Roma nos faz vislumbrar quanta coisa mudou e quanta coisa ainda continua surpreendentemente do mesmo jeito que era, muitas vezes apenas com os nomes trocados. Sim, porque o que se herdou do Império Romano ao longo desses vinte e sete séculos de uso do latim escrito não foi pouco. (VIARO, 1999, p.8-9).
}

Segundo Heck (2013, p.10), “Ao resgatar a cultura da antiguidade greco-latina, o movimento humanista toma consciência do homem como fim [...]". Portanto, ainda que a Lei de Diretrizes e Bases da Educação 9394/1996, em vigor, não faça referências ao ensino de línguas clássicas, nem mesmo à língua latina, cabe aos docentes do ensino fundamental e médio responsáveis pela disciplina de Língua Portuguesa, criarem mecanismos de inserção desse conteúdo, contribuindo para um verdadeiro Letramento de seus alunos no século XXI.

\section{O papel do material didático}

Apesar de o material didático ter como definição "tudo o que é empregado por professores e alunos para facilitar a aprendizagem” (Salas, 2004 apud Vilaça, 2009 p.5), 
o livro é sempre a modalidade mais discutida na literatura e reverenciada pela sociedade em geral.

Portanto, sua escolha não é o suficiente para o sucesso do processo de ensino/aprendizagem. Afinal, a complexidade na utilização desse recurso didático específico se dá em face de vários fatores, tais como: a existência de livros de má e boa qualidade, as dificuldades de disponibilização e acessibilidade aos alunos e professores, o custo sempre elevado da produção livreira no país que geralmente culmina na dificuldade de atualização dos livros.

Além disso, o livro didático impõe ao professor um grau de comprometimento e habilidade ainda maior no exercício da docência, pois, segundo Silva (2009),

\begin{abstract}
A imutabilidade do livro didático e, consequentemente a segurança supostamente suprida por ele são simplesmente um construto inexistente, pois cada sala de aula que utilizar determinado livro poderá obter resultados diferentes. Ou ainda, o mesmo livro didático utilizado na mesma comunidade de aprendizagem em épocas diversas pode apresentar resultados também diferentes. (SILVA, 2009, p.59)
\end{abstract}

O que é acrescido por Little e Perciclová (2006, apud SILVA 2009, p.63), “a ideia de que o livro didático deve, sempre, ser subordinado a um processo de discussão e negociação com os aprendentes e que os professores devem usar o livro com flexibilidade e imaginação".

Portanto, o livro didático é uma realidade no círculo escolar e precisa do docente para fazer sua integração ao processo ensino/aprendizagem de maneira mais harmônica e produtiva; de modo, que tal parceria consiga implementar uma nova realidade de letramento contextualizado e crítico para os alunos.

\title{
O papel da biblioteca para o ensino-aprendizagem de Línguas e de Literaturas
}

Segundo Costa (2013),

\begin{abstract}
A biblioteca integra a escola, disponibiliza informação e auxilia os professores nas ações pedagógicas e no processo de ensinoaprendizagem. Além disso, a biblioteca escolar prepara o indivíduo para a aprendizagem ao longo da vida, proporciona o desenvolvimento do pensamento crítico e inovador, "preparando-os para viver como cidadãos responsáveis" (IFLA, 2000) na atual sociedade da aprendizagem. (COSTA, 2013, p.24)
\end{abstract}

Por essas razões ela desempenha um papel fundamental na construção cultural do indivíduo, no seu processo de aprendizagem, sobretudo de Línguas e Literaturas, 
através da leitura dos mais diferentes gêneros. Afinal, a leitura de um texto projeta o indivíduo numa relação com o autor e com outros indivíduos numa sociedade diversificada.

$\mathrm{Na}$ Idade Média, a leitura era feita via oral, transmitida entre os membros de uma comunidade, passando entre gerações e perpetuando seus conhecimentos. Com a ascensão da burguesia, a partir do século XVIII, uma grande parte da população teve contato com os impressos da época, entre eles, jornais e livros. E, apesar do interesse primeiro ser de divulgação de um mercado consumista, era preciso criar o hábito da leitura para futuros leitores. Assim, incentivou-se a prática de leituras em grupo com o intuito de ensinar normas de cidadania entre os indivíduos de uma comunidade (PAULINO, 2001).

Hoje, tem-se uma forma diversa de divulgar a leitura de diferentes gêneros textuais, seja oralmente, seja registrando sua escrita para a eternidade através dos recursos da tecnologia da informação.

Como se vê, para ser um leitor é preciso que haja algo para se ler. Nessa interação, o autor dever ser livre e criativo, de modo que retrate o belo com tamanha fidedignidade que o leitor possa interagir com os personagens, com a história, para partilhar aos outros a beleza retratada pelo autor; ou seja, o leitor deve participar da escrita do autor para fazer, assim, a sua contação, tornando-se refém e coparticipante da obra.

Ao fazer parte do texto, o leitor inventa outras leituras e, assim como o espaço, o tempo e o ritmo, ele se torna um elemento a mais na esfera textual. Todo texto chama seus leitores para um diálogo. "Como num tear, cabe ao leitor segurar, amarrar e prender os fiapos, deixados ou não intencionalmente pelo autor, para suprir as fissuras e as brechas do tecido" (OLIVEIRA, 2014, p.31).

Portanto, para que essa relação entre o leitor e a leitura de fato se consolide é essencial o papel das bibliotecas, na medida em que estas são capazes de colocar à disposição dos alunos um ambiente que favoreça a formação e desenvolvimento de hábitos de leitura e pesquisa, bem como, oferecer aos professores o material necessário à implementação de seus trabalhos e ao enriquecimento de seus currículos escolares. E nesse sentido, não se podem esquecer as obras de literatura greco-latina, tão importantes ao aprendizado da língua Portuguesa. 


\section{O papel do professor de ensino básico (Fundamental e/ou Médio) sobre os estudos clássicos}

Ao investigar a presença das referências greco-latinas no ensino de língua e literatura portuguesa nos níveis fundamental e médio, é fundamental considerarmos que em um século o qual impera a rapidez do avanço tecnológico, o estudo do Latim pode ajudar a estabelecer uma conexão entre o passado e o presente, capaz de fornecer subsídios para o aperfeiçoamento de nossas habilidades e competências em relação ao ensino-aprendizagem das Línguas e Literaturas.

Vejamos que o latim não é uma língua morta, como dizem, mas no nosso dia-adia temos palavras e expressões que se originam dele, como: habeas corpus; álibi, data vênia (palavras usadas no Direito); quem não enviou um curriculum vitae? Ou, quem já falou em fecundação in vitro? E o que dizer das novas palavras incorporadas ao nosso dicionário, como fax ( $f a c$ símile) e as palavras importadas do inglês que muito usamos na Informática, deletar, do inglês to delete, que origina verbo deleo em latim, que significa “destruir" (VIARO, 1999, p.3).

É por isso que o Plano Curricular Nacional para Língua Portuguesa - Ensino Fundamental II ( $6^{\circ}$ ao $9^{\circ}$ ano) faz a seguinte consideração:

Por meio da linguagem, quadros de referência culturais representações, teorias populares, mitos, conhecimento científico, arte, concepções e orientações ideológicas, inclusive preconceitos pelos quais se interpretam a realidade e as expressões linguísticas. Por outro lado, como atividade sobre símbolos e representações, a linguagem torna possível o pensamento abstrato, a construção de sistemas descritivos e explicativos e a capacidade de alterá-los, reorganizá- los, substituir uns por outros. Nesse sentido, a linguagem contém em si a fonte dialética da tradição e da mudança. Nessa perspectiva, língua é um sistema de signos específico, histórico e social, que possibilita a homens e mulheres significar o mundo e a sociedade. Aprendê-la é aprender não somente palavras e saber combiná-las em expressões complexas, mas apreender pragmaticamente seus significados culturais e, com eles, os modos pelos quais as pessoas entendem e interpretam a realidade e a si mesmas. (MEC, 1998, p.20)

No entanto, percebe-se que a escola na atualidade está mais preocupada em alfabetizar os alunos, com tarefas de ler e escrever, utilizando estratégias didáticas ligadas à leitura de textos para a elaboração e resolução da gramática do que buscar um conhecimento de maior amplitude.

E é por essa razão, que o PCN (1998, p.48) ressalta o papel do professor para cumprir a organização de "ações que possibilitem aos alunos o contato crítico e reflexivo com o diferente e o desvelamento dos implícitos das práticas de linguagem”. 


\section{METODOLOGIA}

Antes de iniciar as etapas desse trabalho, coube aos alunos da disciplina PIPE 3 - Projeto Integrado de Práticas Educativas / Estudos Clássicos na Aprendizagem de Língua Portuguesa e de Literatura, oferecida pelo curso de Letras, da Universidade Federal de Uberlândia, buscar a própria fundamentação teórica para a construção de sua atividade de conclusão.

Desse modo, buscamos realizar diversas leituras de artigos científicos e trabalhos acadêmicos, os quais trouxessem informações relevantes sobre as referências Greco-Latinas na construção da Língua Materna, o papel do material didático, o papel da biblioteca para o ensino-aprendizagem de Línguas e de Literaturas e o papel do professor de ensino básico (Fundamental e/ou Médio) sobre os estudos clássicos, possibilitando um melhor aproveitamento na parte prática da atividade de conclusão, ou seja, em nosso processo investigatório.

\section{Análise de material didático}

Além da fundamentação teórica geral sobre o assunto, aspectos relacionados à análise e elaboração de material didático também foram fundamentados.

Para a realização da análise do material didático, foram escolhidos os seguintes livros para Literatura no Ensino Médio: "Literatura brasileira e portuguesa", de Douglas Tufano, e "Conexões em Língua Portuguesa: Literatura", de Wilton Ormundo e Mara Scorsafava, ambos publicados pela Editora Moderna, em 2012 e 2013 respectivamente.

É importante salientar que, apesar de ambos os livros virem acompanhados de material de apoio digital (DVD), a análise proposta para esse estudo concentrou-se somente no livro-texto. Assim, a proposta de análise consistiu em verificar a presença ou não de indicadores de estudos clássicos, a partir das unidades didáticas estabelecidas em cada obra.

Nesse sentido, verificaram-se alguns aspectos, tais como:

$\rightarrow$ Apresenta elementos teóricos relacionados ao estudo do Latim (sufixos, prefixos etc.);

$\rightarrow$ Proporciona o conhecimento sobre autores e obras da literatura greco-latina, através de textos (traduzidos ou adaptados) ou fragmentos destes; e, 
$\rightarrow$ Favorece a interdisciplinaridade, tanto a interna à área, como na relação entre áreas, por meio de articulações integradoras que se proponham a ultrapassar os limites estritos da disciplina, tais como dicas literárias, filmes, vídeos etc., os quais reafirmam a presença do Latim no cotidiano do aluno.

Diante dos resultados, uma discussão com embasamento teórico foi estabelecida de modo a apresentar considerações que possam contribuir de maneira relevante ao processo de ensino/aprendizagem de Latim, nos ensinos Fundamental e Médio.

\section{Visita à escola}

A pesquisa foi realizada no Colégio Tiradentes da Polícia Militar de Minas Gerais, sede Uberlândia. Trata-se de uma escola pública com um histórico de fundação datado de 1937, cujo objetivo inicial era "oferecer educação escolar aos militares e seus dependentes" (COLÉGIO TIRADENTES DA POLÍCIA MILITAR DE MINAS GERAIS-UBERLÂNDIA, 2015, p.6).

A unidade de Uberlândia iniciou seu trabalho em 2015. Por ser um colégio para atender, inicialmente, filhos e descendentes de até $2^{\circ}$ grau de militares, a escola possui uma "Diretoria administrativa organizada como estrutura administrativa de Comando e uma estrutura pedagógica específica para cada unidade" (COLÉGIO TIRADENTES DA POLÍCIA MILITAR DE MINAS GERAIS-UBERLÂNDIA, 2015, p.7). Na atualidade possui 17 salas de Ensino Fundamental I (do $1^{\circ}$ ao $5^{\circ}$ ano) e 5 salas de Ensino Fundamental II (do $6^{\circ}$ ao $7^{\circ}$ ano). Possui um quadro de professores habilitados nas suas respectivas áreas; bem como, um quadro de funcionários administrativos, composto de militares e civis. O diferencial da instituição está na parceria corpo pedagógico e corpo administrativo. A escola está em expansão.

\section{Entrevista com professores e responsáveis pela Biblioteca}

A mesma foi feita com as professoras de Português e Literatura dos $6^{\circ}(\mathrm{P} 1)$ e $7^{\circ}$ (P2) anos e a Auxiliar Administrativo de Biblioteca (AA1) do turno da manhã.

As entrevistas datam de maio de 2017, nas dependências do colégio visitado, e serão apresentadas na seção dos resultados. 
É importante salientar, desde já, que a pesquisa realizada é de intuito acadêmico e por isso, a transcrição das falas das professoras se deu com preferência à fala culta da língua portuguesa não desrespeitando a fala coloquial utilizada por elas.

\section{RESULTADOS}

\section{Livro 1}

O primeiro livro analisado para esse estudo foi "Literatura brasileira e portuguesa", de Douglas Tufano e publicado pela Editora Moderna. Trata-se de uma obra pertencente à Coleção Vereda Digital, voltada para o Ensino Médio, em volume único e organizada em três partes e 35 capítulos.

À análise investigativa em busca de elementos dos estudos clássicos (grecolatino) no contexto da aprendizagem de Literatura, os achados foram bastante limitados, constituindo-se dos seguintes:

Gráfico 1 - Presença de elementos dos estudos clássicos (Greco-Latinos) no livro didático.

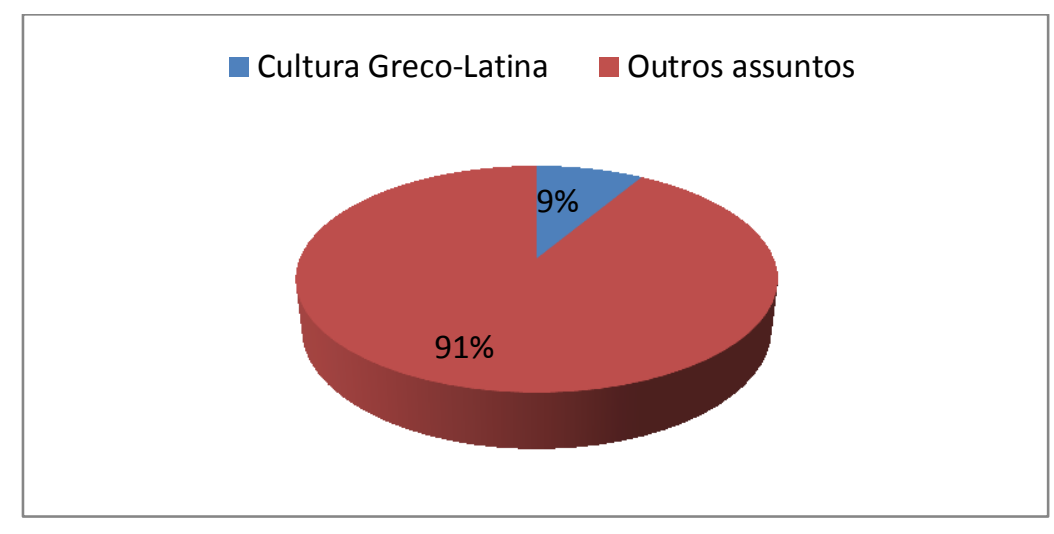

Fonte: As autoras.

\section{Livro 2}

O segundo livro analisado foi "Conexões em Língua Portuguesa: Literatura" (Imagem 4), de Wilton Ormundo e Mara Scorsafava e publicado, também, pela Editora Moderna. Em volume único, foi organizado em 36 capítulos, distribuídos em 15 unidades, finalizadas pelas seções especiais Expressões e Leitura puxa leitura.

Quanto à análise investigativa, os achados foram os seguintes: 
Gráfico 2 - Presença de elementos dos estudos clássicos (Greco-Latinos) no livro didático.

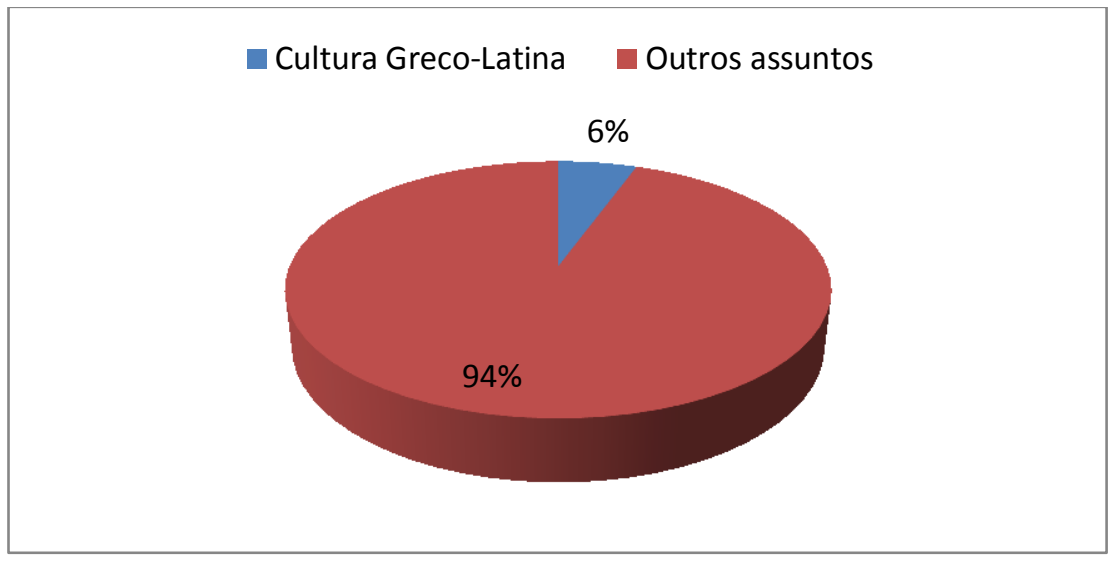

Fonte: As autoras.

\section{Consulta à biblioteca escolar e conversa com a Auxiliar Administrativa de Biblioteca}

A Biblioteca possui um Auxiliar Administrativa de Biblioteca (AA) para cada turno e uma Professora de Uso de Biblioteca (PUB), igualmente, para cada turno. O horário de funcionamento é das $07 \mathrm{~h} 00 \mathrm{~min}$ às $17 \mathrm{~h} 30 \mathrm{~min}$.

Sobre o acervo, apesar de o colégio estar em seu terceiro ano de funcionamento, tem um número razoável de exemplares, todos por meio de doação, seja de familiares dos alunos, amigos e pessoas particulares, seja por parte do governo ${ }^{1}$. Há solicitação, por parte dos alunos, da aquisição de títulos apreciados por eles e que não têm no acervo.

A coordenação do Colégio propõe o incentivo à leitura através da Ciranda de Livros - projeto em parceria com a professora de Português, a Professora de Uso de Biblioteca (PUB) e a Auxiliar Administrativa de Biblioteca (AA) - que acontece com o rodízio de livros a cada 7 dias para os alunos de $1^{\circ}$ ao $3^{\circ}$ ano, e a cada 15 dias para os alunos do $4^{\circ}$ ao $7^{\circ}$ ano. É feita a leitura do livro, o preenchimento de uma ficha literária e o reconto do texto.

Os alunos frequentam a Biblioteca para leitura descompromissada e autônoma nos intervalos de aula e alguns no final do horário enquanto aguardam para ir embora, além do trabalho de sala de aula, quando o professor propõe um trabalho diferenciado.

\footnotetext{
${ }^{1}$ A Biblioteca tem um sistema de catalogação do acervo e de empréstimo no computador e por meio de fichas.
} 
A Biblioteca possui alguns títulos com um número razoável de exemplares, variando entre três e 30 exemplares do mesmo título. Os alunos têm uma preferência pelo gênero Aventura. Quanto ao oferecimento de literatura clássica latina, compõem em seu acervo, exemplares adaptados da Odisseia e Ilíada, de Homero.

A responsabilidade da Professora de Uso de Biblioteca está em montar e realizar projetos que envolvam a leitura e a escrita por parte dos alunos. Mesmo não tendo na grade curricular o nome Literatura, na disciplina de Português é reservada uma aula de sua grade curricular para o trabalho com a leitura, seja em sala de aula, ou na Biblioteca.

As funcionárias da biblioteca procuram oferecer oportunidades, como apresentação de teatro, leitura no palco para as crianças menores, contação de histórias infantis, estimulando os alunos do turno da manhã a se apresentar para os do turno da tarde.

A Auxiliar Administrativa de Biblioteca do turno da tarde é membro desse grupo, ou seja, é coautora desse artigo; por isso, optou por não responder à entrevista, deixando a fala para a Auxiliar do turno da manhã. Contudo, ambas trabalham em conjunto, inclusive os possíveis projetos propostos.

Para que a Biblioteca seja um espaço ideal para um bom trabalho com projetos de leitura, a Auxiliar Administrativa de Biblioteca sugere que estes sejam realizados e propostos de acordo com a realidade da Escola, da família e da sociedade que estamos vivendo hoje e que os alunos possam ter mais acesso à leitura, tornando-se mais críticos e bons escritores.

\section{Entrevista com professoras}

Quanto à metodologia do ensino de literatura, as professoras de Português e Literatura $\operatorname{dos} 6^{\circ}(\mathrm{P} 1)$ e $7^{\circ}(\mathrm{P} 2)$ anos respectivamente, dizem que não é possível haver discussão sobre o seu planejamento, pois o mesmo "vem pronto" da central de Belo Horizonte, onde fica o Departamento de Educação Escolar e Assistência Social da Polícia Militar (DEEAS). A avaliação, por sua vez, pode ser analisada e discutida junto à Supervisora da escola.

Sobre o incentivo a leitura dos clássicos da Literatura Brasileira e da Literatura Greco-latina, procura-se apresentar as diferenças nos estilos. No entanto, as possiblidades são restritas ao programa já estabelecido. 
Para a leitura e produção de textos literários, as referidas professoras de Língua Portuguesa trabalham com a interpretação, ilustração e comentários pessoais dos textos literários oferecidos. Quanto aos clássicos da Literatura Brasileira elas dizem preferir trabalhar com os contemporâneos. Já a P1, apesar do planejamento vir pronto, para torná-lo mais atrativo, ela acrescenta debates e roda de conversas e o faz pelo menos uma vez por semana, unindo a literatura com as aulas de redação. Para tal utiliza os LD, os livros de literatura das etapas ${ }^{2}$, livros da Biblioteca, data show e Histórias em Quadrinhos. Na avaliação, a professora cobra a compreensão, interesse e gosto nos variados estilos de gêneros e, nas provas de Português, a compreensão dos livros literários das etapas.

Quanto ao trabalho de Literatura na escola, a P1 diz que, no formato que está sendo apresentado, este não dá oportunidade de crescimento do aluno. O tempo é curto para produção de projetos variados como saraus e similares. Ela acredita que a elaboração de projetos facilitaria o desenvolvimento da reflexão, sensibilidade, maior compreensão da língua Portuguesa em todos os conteúdos.

Para a P2, apesar de o planejamento vir pronto, o trabalho realizado no colégio é positivo. Porém, com sua experiência em outras escolas estaduais a realidade é diferente. Os projetos desenvolvidos no Colégio Tiradentes da Polícia Militar de Minas Gerais, sede Uberlândia, são os dos livros de literatura das etapas trimestrais e o desenvolvido pela Professora de Uso de Biblioteca e Auxiliar administrativa de Biblioteca. O desenvolvimento de projetos contribui na influência e promoção do aluno para o crescimento e desenvolvimento para o bem escrever. Para ela quanto mais se lê melhor se escreve.

Na reflexão dos pontos positivos e negativos sobre o ensino de literatura nos dias atuais, a P1 acredita que o fato de tê-lo na grade curricular já é positivo. No entanto, deveria ser independente do ensino de Português. Para a P2, esta acredita ser negativo o foco nos clássicos, esquecendo-se dos contemporâneos, e o fato do planejamento vir pronto.

Assim, a entrevista com as professoras demonstra que o trabalho realizado por elas não vai além do tradicional. Procura-se trabalhar mais gramática do que formar o aluno um bom leitor para ser um bom escritor. Quanto aos clássicos, tanto mundiais

\footnotetext{
${ }^{2} \mathrm{O}$ critério de avaliação da disciplina de Português inclui a leitura de 5 a 6 livros de literatura, divididos em três etapas no decorrer do ano, correspondente a cada trimestre.
} 
quanto da Literatura Brasileira, não se dá muita importância, preferindo trabalhar com os contemporâneos.

\section{DISCUSSÃO E CONSIDERAÇÕES FINAIS}

Durante a investigação da presença das referências greco-latinas no ensino de língua e literatura portuguesa nos níveis fundamental e médio, pudemos reafirmar a consciência em relação ao fato de que a linguagem é o que medeia as relações sociais, permitindo a inserção humana neste ou naquele lugar social, posto que a língua supera a ideia de um conjunto de signos e de regras, sendo atravessada por aspectos da ordem do físico, do sociocultural e do psicológico.

Por ser resultado de uma coletividade a língua como forma de expressão social é, então, modificada e enriquecida continuamente, embora isso não signifique romper com conhecimentos passados, como é o caso do ensino das culturas clássicas.

Desse modo, nosso processo investigatório apontou para uma série de fragilidades importantes no processo de construção linguística do aluno, no que diz respeito ao acesso às obras da literatura greco-latina.

Nas análises dos livros do Ensino Médio, verificou-se que os autores têm a preocupação em apresentar aos alunos, conteúdo relacionado aos estudos clássicos, mas há uma limitação em relação à teoria básica. São apresentados poucos textos traduzidos ou adaptados e fragmentados.

Quanto ao trabalho das professoras na escola de Ensino Fundamental visitada, pode-se perceber que há muito que caminhar no sentido de atender às demandas desse conhecimento. Não há indícios de incentivo por parte delas e o trabalho feito pela equipe de Biblioteca ainda é precário, pois não há acervo considerável para a aplicação de uma atividade mais aprofundada.

Diante desses achados, pode-se pensar que em longo prazo a carência das bases greco-latinas para o aprendizado da Língua Portuguesa, poderá ocasionar o gradual desinteresse dos alunos pelo aprendizado da Língua Materna, culminando na ampliação de suas dificuldades em relação a esse conteúdo. As lacunas deixadas pela falta de fundamentação linguística, no tocante aos estudos clássicos, tendem a deixar sem respostas muitos dos questionamentos dos alunos. Assim, sem tais respostas que lhes satisfaçam a curiosidade e facilitem o seu aprendizado, uma porta se abre ao desinteresse do aprendiz e a limitação do seu próprio letramento. 


\section{REFERÊNCIAS}

BRASIL. Lei $n^{\circ}$. 4.024, de 20 de Dezembro de 1961. Fixa as Diretrizes e Bases da Educação Nacional. Diário Oficial da república Federativa do Brasil, Brasília, DF, 27 dez. 1961. (Retificado em 28 dez. 1961).

Lei $n^{\circ} .9 .394$, de 20 de Dezembro de 1996. Estabelece as diretrizes e bases da educação nacional. Diário Oficial da república Federativa do Brasil, Brasília, DF, 23 dez. 1996.

COLÉGIO TIRADENTES DA POLÍCIA MILITAR DE MINAS GERAISUBERLÂNDIA. Projeto Político Pedagógico - PPP. Uberlândia, 2015.

COSTA, J. F. O papel da biblioteca escolar no processo de ensino-aprendizagem. 2013. 95f. Monografia (Graduação em Biblioteconomia) - Faculdade de Ciência da Informação, Universidade de Brasília, Brasília, DF, 2013.

HECK, M. R. D. O Ensino do Latim no Brasil: objetivos, método e tradição. 2013. 35f. Trabalho de Conclusão de Curso (Licenciatura em Letras com ênfase em Português- Latim), Universidade Federal do Rio Grande do Sul, Porto Alegre, 2013.

LONGO, G. A Abordagem Textual no Ensino de Latim. Organon, Porto Alegre, 29(56), p. 175-188, 2014.

MINISTÉRIO DA EDUCAÇÃO. Parâmetros curriculares nacionais: terceiro e quarto ciclos do ensino fundamental: língua portuguesa. Brasília: MEC/SEF, 1998. $106 \mathrm{p}$.

OLIVEIRA, M. M. Imagens e representação do professor em Clarissa e Música ao longe, de Erico Verissimo. Novas Edições Acadêmicas, Saarbrücken, 2014. Disponível em www.get-morebooks.com.

ORMUNDO, W.; SCORSAFAVA, M. Conexões em Língua Portuguesa: Literatura. São Paulo: Moderna, 2012. (Manual do professor).

PAULINO, G. et al. Pensando a leitura. In: leitura. Belo Horizonte: Formato Editorial, 2001. p. 11-44.

Tipos de texto, modos de

SILVA, W. M. e. Livros Didáticos: Fomentadores ou inibidores da autonomização? In: DIAS, R.; CRISTOVÃO, V. L. L. (Org.). O Livro Didático de língua Estrangeira: múltiplas perspectivas. Campinas, SP: Mercado de Letras, 2009. p. 57-78.

TUFANO, D. Literatura brasileira e portuguesa. São Paulo: Moderna, 2012. (Manual do professor).

UNIVERSIDADE FEDERAL DE UBERLÂNDIA. Projeto Político Pedagógico do Curso de Letras. Coordenação do Curso de Letras, Uberlândia, 2007. Disponível em: http://www.ileel.ufu.br/letras/wpcontent/uploads/2015/04/PROJETO_POLITICO_PEDAGOGICO_LETRAS.pdf. 
VIARO, M. E. A importância do Latim na atualidade. Revista de ciências humanas e sociais - Unisa, São Paulo, v. 1, n. 1, p. 7-12, 1999.

VILAÇA, M. L. C. O material didático no ensino de língua estrangeira: definições, modalidades e papeis. Revista Eletrônica do instituto de Humanidades, Rio de Janeiro, v. 8, n. 30, pp. 1-14, jul./set. 2009. Disponível em: < http://publicacoes.unigranrio.com.br/index.php/reihm/article/view/653>

\section{AS AUTORAS}

Alessandra Leles Rocha é graduanda em Letras - Habilitação em Inglês e Literaturas de Língua Inglesa, Bacharel em Ciências Biológicas e Mestre em Geografia (Área de Concentração: Análise, Planejamento e Gestão Socioambiental), pela Universidade Federal de Uberlândia.

E-mail: lelesrocha.a@gmail.com

Maria Marta Carrijo de Oliveira é graduanda em Letras - Habilitação em Português e Literaturas de Língua Portuguesa, Bacharel e Licenciada em Psicologia e Mestre em Teoria Literária, pela Universidade Federal de Uberlândia.

E-mail: mcarrijodeoliveira@yahoo.com.br 